\title{
Simultaneous DNA and RNA isolation from brain punches for epigenetics
}

\author{
Marc Bettscheider, Chris Murgatroyd ${ }^{*}$ and Dietmar Spengler
}

\begin{abstract}
Background: Epigenetic modifications such as DNA methylation play an important role for gene expression and are regulated by developmental and environmental signals. DNA methylation typically occurs in a highly tissueand cell-specific manner. This raises a severe challenge when studying discrete, small regions of the brain where cellular heterogeneity is high and tissue quantity limited. Because gene expression and methylation are often tightly linked it appears of interest to compare both parameters in the same sample.
\end{abstract}

Findings: We present a refined method for the simultaneous extraction of DNA for bisulfite sequencing and RNA for expression analysis from small mouse brain tissue punches. This method can also be easily adapted for other small tissues or cell populations.

Conclusions: The method described herein results in DNA and RNA of a quantity and quality permitting highly reliable bisulfite analysis and quantitative RT-PCR measurements, respectively.

\section{Background}

The spatio-temporal expression of a gene is defined by DNA sequence (per se) and the manner by which it is marked through epigenetic mechanisms including DNA methylation and chromatin modification. In eukaryotes DNA methylation typically comprises the covalent addition of a methyl group at the 5-position of cytosines that are followed by guanines, i.e. CpG dinucleotides. Functionally, DNA methylation frequently confers gene silencing.

CpG methylation of genomic DNA is routinely analyzed by the treatment of DNA with sodium bisulfite, followed by PCR amplification and sequencing [1]. While bisulfite readily deaminates cytosine residues to uracils, which are then converted to thymines during DNA amplification by PCR, 5-methylcytosine resists this modification. Many methods based on this principle have been developed including direct sequencing, pyrosequencing, methylation-specific PCR (MSP), combined bisulfite restriction analysis (COBRA), methylation-sensitive single nucleotide primer extension (MS-SNuPE) and microarray-based methods (for review see [2]).

\footnotetext{
* Correspondence: murgatroyd@mpipsykl.mpg.de

Department of Molecular Neuroendocrinology, Max-Planck-Institute of Psychiatry, Kraepelinstr. 2-10, 80804 Munich, Germany
}

Bisulfite analysis depends on high quantity and quality of DNA as the bisulfite conversion procedure itself requires long incubation times, elevated temperature, and high bisulfite concentration; all of which are highly detrimental to DNA [3]. Furthermore, to investigate the functional interrelationship between DNA methylation and RNA expression both should be determined within the same sample. In this respect, the analysis of expression data and DNA methylation from two separate cohorts of animals may introduce a bias, unless at least double the numbers of animals are included in each cohort. Similarly, the surgical splitting of tissues containing different cell types can confound the analysis as DNA methylation is highly tissue- and even cell-type specific. Finally, tissue punches of usually around 0.8 $\mathrm{mm}$ from distinct areas of the brain, are generally rather limiting.

Though a number of different methods have been developed for simultaneous extraction of DNA and RNA, a technique addressing efficient isolation from small tissue samples has not been reported so far. While TRIzol can be used for the simultaneous extraction of DNA and RNA, in addition to proteins [4], we note that that the quality of DNA produced from small tissues was not high enough for bisulfite analysis. Furthermore, we find that commercially available kits for RNA/DNA 
isolation, relying on spin-column purification [5], do not yield a high enough DNA quantity from small tissues to permit reliable bisulfite analysis (data not shown).

We have therefore adapted a derivative of the guanidinium thiocyanate-phenol-chloroform extraction method, originally devised by Piotr Chomczynski and Nicoletta Sacchi for the extraction of RNA [6]. While variants of a guanidinium thiocyanate-based (GTC) buffer have been used for RNA (for review see [7]), various forms of a guanidinium thiocyanate-based buffer have also proved efficient for the purification of DNA [8-12] and can be further modified for the simultaneous extraction of RNA and DNA in cancer tissues [13] and whole fish embryos [14]. Here we describe our experience in extracting both DNA and RNA from punched brain tissue and present an alternative for obtaining both DNA and RNA from the same cells for genome and transcriptome profiling. In addition, we characterized tissue specimens and cell quantities needed for this method.

\section{Materials and Methods}

Tissue punches with $0.8 \mathrm{~mm}$ in diameter were taken from various brain regions including cortex, paraventricular nucleus (PVN) and dentate gyrus of C57/BL6 mice (Charles River) and were frozen at $-80^{\circ} \mathrm{C}$ until nucleotide extraction. In addition smaller tissue punches of 0.3 $\mathrm{mm}$ diameter were taken from the cortex. To assess the sensitivity of the assay different numbers of Neuro2a (ATCC number CCL-131) cells were pelleted and subjected to the same isolation protocol. Initially we compared commonly used isolation methods to the simultaneous isolation of DNA and RNA from a single punch. Cortex punches $(0,8 \mathrm{~mm})$ were subjected to various DNA (Qiagen DNeasy Blood \& Tissue Kit; CTAB method [15]; SDS/Proteinase K [16]; Gentra Puregene Tissue Kit) and RNA (Macherey Nagel NucleoSpin ${ }^{\circledR}$ RNA II; TRIzol ${ }^{\circledR}$ Reagent; Chomczynski protocol [7]) extraction protocols (Table 1).

RNA/DNA yield, A260/280 and 260/230 ratios for the extracted samples were analyzed with an Implen Nanophotometer.

For simultaneous extraction, tissue punches were homogenized using a pipette and vortexer in $400 \mu \mathrm{l}$ of guanidinium thiocyanate (GTC) buffer (4.5 M guanidinium thiocyanate, $2 \%$ N-lauroylsarcosine, $50 \mathrm{mM}$ EDTA $\mathrm{pH} 8,25 \mathrm{mM}$ Tris- $\mathrm{HCl} \mathrm{pH}$ 7.5, $0.1 \mathrm{M}$ beta-mercaptoethanol, $0.2 \%$ antifoam $\mathrm{A}$ ) at room temperature and further passed several times through a hypodermic syringe (29G) (Figure 1). The guanidinium thiocyanate, along with the 2-mercaptoethanol and sarcosine, denatures proteins, including DNases and RNases. The lysate is then split into two equal parts and processed separately for RNA and DNA. Note that it is possible to divide the sample unequally depending on the demand
Table 1 Yield and purity of DNA and RNA preparations from $0,8 \mathrm{~mm}$ cortex punches using commonly employed protocols, commercially available kits and the presented simultaneous DNA/RNA extraction method

\begin{tabular}{lllll}
\hline Method DNA & & $\begin{array}{l}\text { Total yield } \\
\text { [ng] }\end{array}$ & $\begin{array}{l}\mathbf{2 6 0 /} \\
\mathbf{2 8 0}\end{array}$ & $\begin{array}{l}\mathbf{2 6 0 /} \\
\mathbf{2 3 0}\end{array}$ \\
\hline $\mathbf{n = 6}$ ) & $\begin{array}{l}\text { Qiagen } \\
\text { Dneasy }\end{array}$ & $360 \pm 96$ & 1,8 & 1,35 \\
& CTAB & $520 \pm 87$ & 1,8 & 1,5 \\
& SDS/Prot K & $850 \pm 195$ & 2 & 1,4 \\
& Gentra & $360 \pm 96$ & 2 & 1,5 \\
& Puregene & & & \\
Method RNA & & & & \\
(n=6) & MN & $366 \pm 75$ & 2,1 & 0,2 \\
& Nucleospin II & & & \\
& Trizol & $690 \pm 262$ & 1,7 & 0,6 \\
Simultaneous DNA/ & Chomczynski & $838 \pm 321$ & 1,9 & 1,4 \\
RNA & & & & \\
(n=9) & DNA & $765 \pm 163$ & 1,9 & 1,3 \\
& RNA & $330 \pm 54$ & 1,9 & 1,2 \\
\hline
\end{tabular}

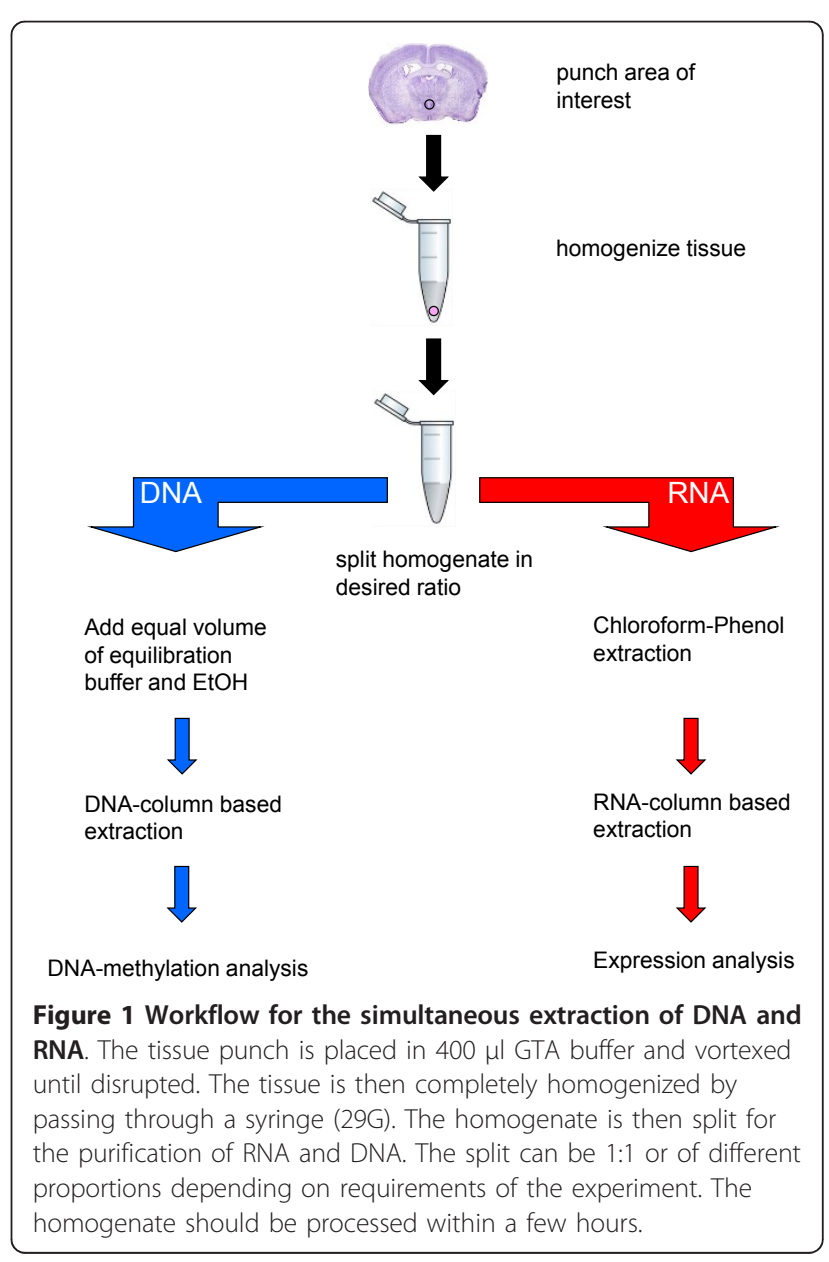


Table 2 Yields of simultaneously isolated RNA and DNA from brain tissue punches $(0,8 \mathrm{~mm})$ of different brain regions and whole pituitary

\begin{tabular}{ccccccc}
\hline Tissue & Total DNA yield $[\mathbf{n g}]$ & A260/280 & $\mathbf{2 6 0 / 2 3 0}$ & Total RNA yield [ng] & A260/280 & 260/230 \\
\hline PVN $(\mathbf{n}=\mathbf{1 0})$ & 980 & 1,9 & 1,3 & 510 & 1,7 & 1 \\
\hline DG $(\mathbf{n}=\mathbf{3 9})$ & 1165 & 1,9 & 1,2 & 275 & 1,9 & 1,1 \\
\hline Cortex $(\mathbf{n}=\mathbf{9})$ & 675 & 1,9 & 1,4 & 330 & 1,9 & 1,2 \\
\hline Pituitary $(\mathbf{n}=\mathbf{2 9})$ & 11400 & 1,9 & 1,9 & 1425 & 1,78 & 1,8 \\
\hline
\end{tabular}

for higher yields of either RNA or DNA. Given that RNA is far less stable than DNA, we suggest processing the RNA first while the DNA can be left for some hours at room temperature.

Briefly, for purification of RNA one half of the lysate is added to $1 / 10$ volume of $\mathrm{NaOAc}, 1$ volume acidic phenol and 1/2 volume of chloroform:isoamyl. The mixture is incubated on ice for $10 \mathrm{~min}$, centrifuged for 20 $\min$ at $13,000 \mathrm{rpm}$ at $4^{\circ} \mathrm{C}$. The aqueous phase is transferred to a new tube and mixed with $70 \% \mathrm{EtOH}$ to precipitate the RNA. The precipitate is then transferred to an RNA spin column (Macherey Nagel) and further processed according to the manufacturer's protocol including an on-column DNase-digestion. We found little difference in RNA quality or quantity between a number of commercially available spin columns (data not shown). Tissue punches as small as $0.8 \mathrm{~mm}$ diameter and 2,000 Neuro2a cells gave sufficient yield and quality of RNA (Table 2 and 3) to allow for RT-PCR analysis. However, yields of RNA from $0.3 \mathrm{~mm}$ punches were more variable suggesting that tissue quantity becomes a limiting factor.

For purification of the DNA the other half of the lysate is equilibrated with equal volumes of Buffer $\mathrm{AL}$ and $100 \% \mathrm{EtOH}$ and loaded on a Spin Column (Qiagen, DNeasy Blood and Tissue Kit). After subsequent washing steps according to the manufacturer's protocol the DNA is eluted with $70^{\circ} \mathrm{C}$ warm Buffer AE after a 10 min pre-incubation at $70^{\circ} \mathrm{C}$. All tissue punches yielded enough DNA (Table 2) for sodium bisulfite treatment using $100 \mathrm{ng}$ of DNA with the Epitect bisulfite kit
(Qiagen). Starting material of less than 5,000 Neuro2a cells did not yielded satisfactory quantities of DNA (Table 3).

\section{Results and Discussion}

DNA and RNA yields and absorbance rates for all methods studied are listed in Table 1. The most efficient method for brain tissue punches among the different DNA extraction protocols is the SDS/Proteinase K method with a total yield of $850 \mathrm{ng}$ per punch followed by the CTAB method (550 ng) and the DNeasy and Puregene isolation Kits (both $360 \mathrm{ng}$ ). All methods resulted in A260/280 values between 1,8 and 2,0 indicating only minor protein contamination. For the tested RNA methods, the Chomczynski protocol yielded the highest amount of RNA per punch (838 ng) with an A260/280 ratio of 1,9 , indicating rather pure RNA. The Trizol method resulted in slightly less RNA (690 ng) and low A260/280 values of 1,7 indicating some protein contamination. The MN Nucleospin columns gave the least amount of RNA (366 ng).

The newly developed simultaneous DNA and RNA extraction had the highest DNA recovery with $765 \mathrm{ng}$ per punch considering that just half a punch is subjected to extraction. The RNA yield from the simultaneous extraction is comparable to the Trizol method, but with a higher purity as indicated by the A260/280 ratio of 1,9 .

Low yields of DNA and RNA led to reduced 260/230 ratios for all methods tested, however, increasing the starting material improved this parameter (Table 3).

Table 3 Yields of simultaneously isolated RNA and DNA from decreasing numbers of Neuro2a cells

\begin{tabular}{|c|c|c|c|c|c|c|}
\hline Cell number $(n=3)$ & Total DNA yield $[\mu \mathrm{g}]$ & $\mathrm{A} 260 / 280$ & $\mathrm{~A} 260 / 230$ & Total RNA yield $[\mu \mathrm{g}]$ & A260/280 & A260/230 \\
\hline 500000 & $31 \pm 1$ & 2 & 2 & $12,7 \pm 0,4$ & 2 & 1,9 \\
\hline 200000 & $13 \pm 0,8$ & 2 & 2,1 & $5,4 \pm 0,13$ & 2 & 2 \\
\hline 100000 & $6,7 \pm 0,6$ & 2 & 2,1 & $2,8 \pm 0,05$ & 2 & 1,8 \\
\hline 50000 & $3,3 \pm 0,25$ & 2 & 1,4 & $1,44 \pm 0,14$ & 1,9 & 1,4 \\
\hline 20000 & $1,5 \pm 0,07$ & 1,9 & 1,5 & $0,59 \pm 0,05$ & 1,9 & 1,1 \\
\hline 10000 & $0,81 \pm 0,07$ & 2 & 1,1 & $0,41 \pm 0,02$ & 1,8 & 0,9 \\
\hline 5000 & $0,46 \pm 0,06$ & 1,9 & 0,9 & $0,29 \pm 0,03$ & 1,6 & 0,7 \\
\hline 2000 & $0,2 \pm 0,05$ & 1,9 & 0,6 & $0,25 \pm 0,013$ & 1,8 & 0,5 \\
\hline
\end{tabular}




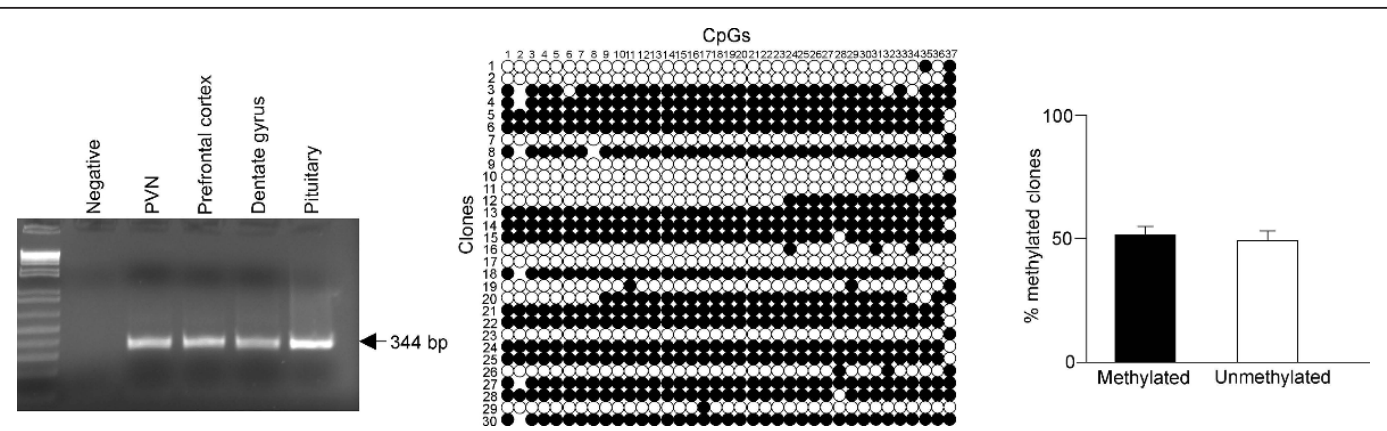

Figure 2 Bisulfite sequencing of DNA from brain tissue punches. DNA (100 ng) from PVN tissue punches $(n=5)$ were separately bisulfite treated. Bisulfite primers directed against the mouse Zacl differentially methylated region (DMR) were used in a PCR. The amplified products were then cloned and DNA from 30 separate recombinant colonies sequenced. Data analysis revealed that the Zac1 locus is methylated at levels of $52 \% \pm 5 \%$ corresponding to current literature that the gene is maternally imprinted.

Importantly, downstream applications such as PCR, RTPCR, bisulfite treatment and subsequent bisulfite PCR are not compromised by lower $260 / 230$ values, as shown below. Nevertheless, other downstream applications should be tested prior to sample processing.

The suitability of the extracted DNA for bisulfite analysis was investigated by using primers (F, ggtattaggtttagagtttatt; $\mathrm{R}$, ttctccaacctcactcrccta) corresponding to the imprinted $Z a c 1$ gene [17]. The promoter of the maternally imprinted Zac1 gene is DNA methylated on only the maternal derived allele; therefore bisulfite sequencing should yield ratios of $50 \%$ methylation at each CpG in the promoter if the extracted DNA is of a sufficient quality and quantity. Indeed, we detected that DNA from PVN tissues gave an average of $52 \% \pm 5 \%$ (Figure 2) supporting that DNA isolated from relatively small brain punches allow for robust DNA methylation analysis.

The quality of the extracted RNA was further examined using the Agilent Bioanalyzer 2100 resulting in RIN scores ranging from 8-10 (Figure 3) indicating undegraded RNA of high quality. The RNA could be further reverse transcribed (Superscript II, Invitrogen)

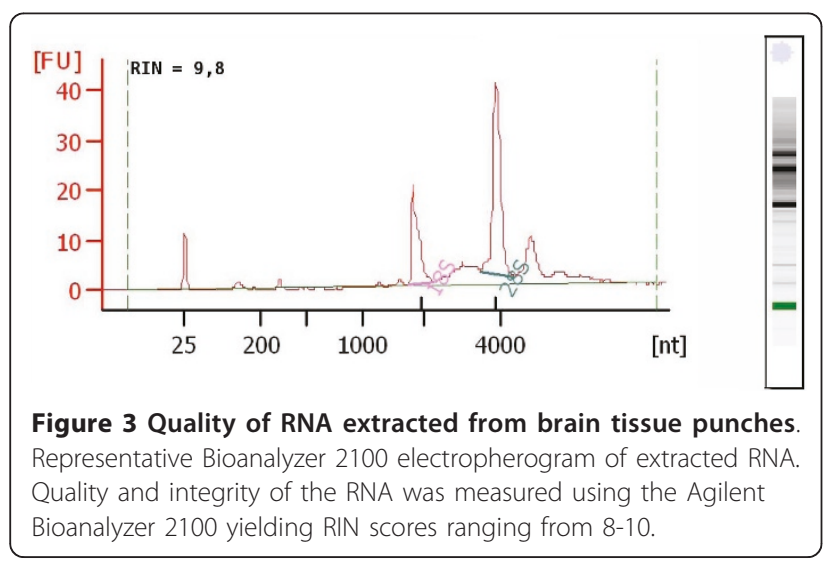

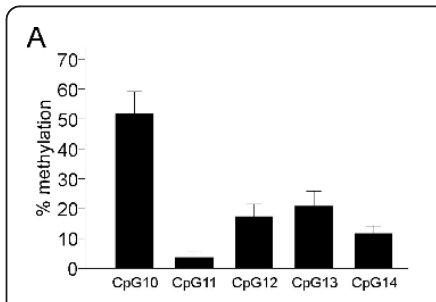
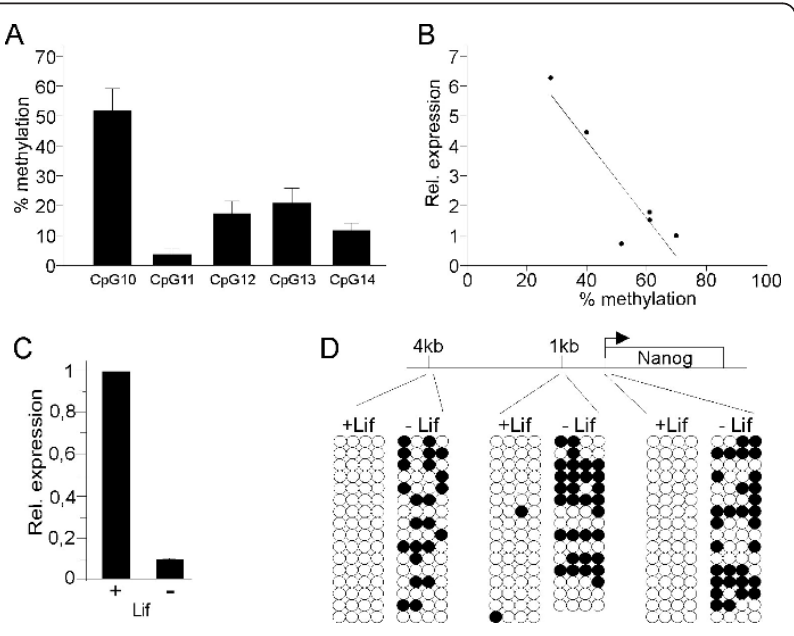

Figure 4 Analysis of gene transcription and methylation from stem cells and brain punches. (A) DNA and RNA were simultaneously extracted from PVN tissue punches of Bl6 mice. Bisulfite treated (Qiagen) DNA was amplified using bisulfite primers directed against a region of the mouse AVP gene enhancer [18].

The amplified products were then cloned in a pGEM vector (Promega) and 16 recombinant colonies sequenced using T7 primer. (B) RNA (100 ng) was reverse transcribed and then subjected to quantitative realtime PCR using primers against AVP CDNA [18]. AVP gene expression was correlated with methylation at individual CpGs revealing that methylation at CpG10 DNA negatively correlates with AVP expression $\left(R^{2}=0.8259\right)$. (C) Differentiated [+Lif] and undifferentiated [-Lif] mouse ES cells [19] were simultaneously extracted for RNA and DNA. RNA (100 ng) was reverse transcribed and then subjected to quantitative realtime PCR (Nanog F agggtctgctactgagatgctctg, R - caaccactggttttctgccaccg) and normalized to the expression of the housekeeping gene HPRT ( $F$ acctctcgaagtgttggatacagg, $R$ - cttgcgctcatcttaggctttg). (D) DNA (100 ng) from undifferentiated and differentiated cells was bisulfite treated and amplified using primers directed against the indicated regions of the mouse Nanog gene (4kb F -

tttgtaggtgggattaattgtgaat, R - aaaaaaacaaaacaccaaccaaat; 1 Kb F ggaagattaggagtttgggattagt, $R$ - atctaccaccatacccaatttaaaa; proximal promoter F - ggtagtttgttgggttttgtatttt, R - aactcttatctccccattcctaaac) and 16 recombinant colonies sequenced. Following differentiation the Nanog promotor becomes methylated and gene expression silenced. 
and produced reliable products with a number of housekeeping and tissue specific genes.

The DNA and RNA extracted from this procedure was also tested for simultaneous bisulfite sequencing and quantitative real time RT-PCR experiments. As a proof of principle we investigated $7 \mathrm{PVN}$ samples for Arginine Vasopressin $(A V P)$ expression and DNA methylation and confirmed negative correlations (Figure 4A,B) as previously described [18]. Moreover, using this method we have been able to study DNA methylation and gene expression during differentiation of embryonic stem cells. We find that differentiation of mouse ES cells [19] leads to silencing of the pluripotency marker gene, Nanog, and this correlates with methylation of promoter regions, important in Nanog regulation [20] (Figure 4C,D).

In summary, we have refined and verified a streamlined protocol for the isolation of high qualities and quantities of DNA and RNA from small tissues for the study of DNA methylation and mRNA expression. Such a procedure will facilitate the analysis of the role of DNA methylation on gene expression through direct correlation analysis.

\section{Acknowledgements}

This work was funded by the European Union (CRESCENDO - EU Contract No. LSHM-CT-2005-018652 to O.F.X. Almeida and D. Spengler).

\section{Authors' contributions}

$\mathrm{MB}$ and $\mathrm{CM}$ performed the experiments. All authors contributed to the conception, design, analysis, interpretation of the data and drafting of the manuscript.

\section{Competing interests}

The authors declare that they have no competing interests.

Received: 25 March 2011 Accepted: 30 August 2011

Published: 30 August 2011

\section{References}

1. Clark SJ, Harrison J, Paul CL, Frommer M: High sensitivity mapping of methylated cytosines. Nucleic Acids Res 1994, 22:2990-7.

2. Laird PW: Principles and challenges of genome-wide DNA methylation analysis. Nat Rev Genet 2010, 11:191-203.

3. Grunau C, Clark SJ, Rosenthal A: Bisulfite genomic sequencing: systematic investigation of critical experimental parameters. Nucleic Acids Res 2001, 29:65.

4. Chey S, Claus C, Liebert UG: Improved method for simultaneous isolation of proteins and nucleic acids. Anal Biochem 2010, 411:164-6.

5. Xu C, Houck JR, Fan W, Wang P, Chen Y, Upton M, Futran ND, Schwartz SM, Zhao LP, Chen C, Mendez E: Simultaneous isolation of DNA and RNA from the same cell population obtained by laser capture microdissection for genome and transcriptome profiling. J Mol Diagn 2008, 10:129-34.

6. Chomczynski P, Sacchi N: Single-step method of RNA isolation by acid guanidinium thiocyanate-phenol-chloroform extraction. Anal Biochem 1987, 162:156-9.

7. Chomczynski P, Sacchi N: The single-step method of RNA isolation by acid guanidinium thiocyanate-phenol-chloroform extraction: twentysomething years on. Nat Protoc 2006, 1:581-5.
8. Lippke JA, Strzempko MN, Raia FF, Simon SL, French CK: Isolation of intact high-molecular-weight DNA by using guanidine isothiocyanate. Appl Environ Microbiol 1987, 53:2588-9.

9. Wright TL, Mamish D, Combs C, Kim M, Donegan E, Ferrell L, Lake J, Roberts J, Ascher NL: Hepatitis B virus and apparent fulminant non-A, non-B hepatitis. Lancet 1992, 339:952-5.

10. de Tomaso AW, Weissman IL: Construction and characterization of largeinsert genomic libraries (BAC and fosmid) from the Ascidian Botryllus schlosseri and initial physical mapping of a histocompatibility locus. Mar Biotechnol (NY) 2003, 5:103-15.

11. Kotlowski R, Martin A, Ablordey A, Chemlal K, Fonteyne PA, Portaels F: Onetube cell lysis and DNA extraction procedure for PCR-based detection of Mycobacterium ulcerans in aquatic insects, molluscs and fish. J Med Microbiol 2004, 53:927-33.

12. Dyachenko V, Beck E, Pantchev N, Bauer C: Cost-effective method of DNA extraction from taeniid eggs. Parasitol Res 2008, 102:811-3.

13. Coombs LM, Pigott D, Proctor A, Eydmann M, Denner J, Knowles MA: Simultaneous isolation of DNA. RNA, and antigenic protein exhibiting kinase activity from small tumor samples using guanidine isothiocyanate. Anal Biochem 1990, 188:338-43.

14. Triant DA, Whitehead A: Simultaneous extraction of high-quality RNA and DNA from small tissue samples. J Hered 2009, 100:246-50.

15. Winnepenninckx B, Backeljau T, De Wachter R: Extraction of high molecular weight DNA from molluscs. Trends Genet 1993, 9:407.

16. Strauss WM: Preparation of genomic DNA from mammalian tissue. In Current protocols in molecular biology. Volume 2. Edited by: Ausubel F M, Brent R, Kingston R E, Moore D D, Seidman J G, Smith J A, Struhl K. New York: John Wiley 1998, 2.2.1-2.2.3.

17. Varrault A, Bilanges B, Mackay DJ, Basyuk E, Ahr B, Fernandez C, Robinson DO, Bockaert J, Journot $\mathrm{L}$ : Characterization of the methylationsensitive promoter of the imprinted ZAC gene supports its role in transient neonatal diabetes mellitus. J Biol Chem 2001, 276:18653-6.

18. Murgatroyd C, Patchev AV, Wu Y, Micale V, Bockmühl Y, Fischer D, Holsboer F, Wotjak CT, Almeida OF, Spengler D: Dynamic DNA methylation programs persistent adverse effects of early-life stress. Nat Neurosci 2009, 12:1559-66.

19. Ikeda H, Osakada F, Watanabe K, Mizuseki K, Haraguchi T, Miyoshi H, Kamiya D, Honda Y, Sasai N, Yoshimura N, Takahashi M, Sasai Y: Generation of Rx+/Pax6+ neural retinal precursors from embryonic stem cells. Proc Natl Acad Sci USA 2005, 102:11331-6.

20. Nettersheim D, Biermann K, Gillis AJ, Steger K, Looijenga LH, Schorle H: NANOG promoter methylation and expression correlation during normal and malignant human germ cell development. Epigenetics 2001, 6:114-22.

doi:10.1186/1756-0500-4-314

Cite this article as: Bettscheider et al: Simultaneous DNA and RNA isolation from brain punches for epigenetics. BMC Research Notes 2011 4:314.

\section{Submit your next manuscript to BioMed Central and take full advantage of:}

- Convenient online submission

- Thorough peer review

- No space constraints or color figure charges

- Immediate publication on acceptance

- Inclusion in PubMed, CAS, Scopus and Google Scholar

- Research which is freely available for redistribution 